\title{
O POTENCIAL DO BAMBU NA MINIMIZAÇÃO DOS PROBLEMAS CLIMÁTICOS NOS ESPAÇOS URBANOS
}

\author{
Vera Cristina Osse ${ }^{1}$ \\ Célia Regina Moretti Meirelles ${ }^{2}$
}

1 Arquiteta e Urbanista. Doutora em Paisagem e Ambiente pela FAU-USP. Leciona na Faculdade de Arquitetura e Urbanismo da Universidade Presbiteriana Mackenzie. E-mail: vosse10@uol.com.br 2 Engenheira civil, Doutora em Engenharia Civil pela Escola Politécnica da USP. Leciona na Faculdade de Arquitetura e Urbanismo da Universidade Presbiteriana Mackenzie.

E-mail: cerellesm@mackenzie.com.br

\begin{abstract}
Resumo
O trabalho discute os problemas gerados pelo aquecimento global e levanta possíveis alternativas que, se aliadas a esforços conjuntos, poderão minimizar os impactos gerados pela humanidade ao se apropriar indevidamente dos recursos naturais. Em um primeiro momento, avalia os efeitos e as mudanças sentidas nos centros urbanos devido ao aquecimento global e, em um segundo momento, avalia a possibilidade de se amenizarem esses impactos, por meio da ampliação de áreas verdes, priorizando a utilização da espécie bambu, que tem grande capacidade de absorção de dióxido de carbono. Os resultados encontrados destacam a importância de se ampliar a quantidade e a aplicação do bambu nas vias públicas, parques e parques lineares, valendose de um manejo controlado das diversas espécies, especialmente na cidade de São Paulo.
\end{abstract}

Palavras-chave: bambu, mudanças climáticas, parques, áreas verdes, espaço urbano. 


\title{
THE POTENTIAL OF BAMBOO IN MINIMIZING THE WEATHER PROBLEMS IN URBAN AREAS
}

\begin{abstract}
The paper discusses the problems caused by global warming, and raises possible alternatives that if combined with joint efforts can minimize the impacts generated by humanity that misappropriate natural resources. At first assesses effects and changes experienced in urban centers by global warming, and then evaluate the possibility of mitigating these impacts through the expansion of green areas, prioritizing the use of bamboo species, which has greater capacity to absorb carbon dioxide. The results highlight the importance of increasing the amount and application of bamboo on public roads, parks and linear parks, through the sort of the various species, especially in the city of São Paulo.
\end{abstract}

Key words: bamboo, climate change, parks, green areas, urban space, public roads.

\section{INTRODUÇÃO}

Como pensar em uma forma de fazer com que a sociedade crie novas bases para se relacionar com a natureza? O homem em si é natureza, faz parte dela, mas não consegue estabelecer uma forma racional de apropriação no domínio dos recursos, na qual o consumo passa a ser o objetivo e o supérfluo a necessidade. Trata-se, portanto, de uma reflexão no sentido de mudar o foco do pensar da sociedade, bem como da busca de novas alternativas referentes ao modo de viver do ser humano.

Ao intervir no espaço da cidade, os arquitetos transformam a sua paisagem e induzem as relações sociais que ali acontecem. A paisagem é algo dinâmico, que reflete diferentes momentos de diferentes gerações, diferentes culturas que se sobrepõem no mesmo lugar. Esta traduz um processo dialético e holístico no espaço, repleto de conexões. Portanto, os espaços públicos devem fazer parte da vivência das pessoas na cidade. Um projeto, ao compreender um determinado sítio, valoriza seu espaço físico e transmite diferentes mensagens de apropriação desse local, sensibiliza e induz às novas formas de usufruto desse espaço. 
Porém, os impactos causados pelas mudanças climáticas, e sua relação com os gases de efeito estufa, têm ampliado as discussões sobre a sustentabilidade do planeta. Vários fenômenos ocorridos nos últimos anos têm demonstrado a precariedade dos sistemas urbanos: ondas de calor na Europa, em 2003; o furacão Katrina nos Estados Unidos, em 2005; as inundações na China, em 2010; as chuvas torrenciais no Brasil, em 2011, provocando deslizamentos de terra na região serrana do Rio de Janeiro. Esses fenômenos têm provocado um grande número de mortes e deixado desabrigado um grande número de pessoas. Alguns pesquisadores associam o aumento e a intensidade de fenômenos da natureza, nos últimos vinte anos, ao aquecimento da terra e ao efeito estufa.

Esta pesquisa visa refletir sobre o grande desafio ambiental deste século, o aquecimento global, e levantar possíveis alternativas que, se aliadas a esforços conjuntos, poderão vir a minimizar esse grande impacto gerado pela humanidade ao se apropriar indevidamente dos recursos naturais.

Em um primeiro momento, avaliam-se os efeitos e as mudanças climáticas sentidas nos centros urbanos, devido ao aquecimento global e, em um segundo momento, levanta-se a possibilidade de se amenizarem os impactos ampliando as áreas verdes, priorizando a aplicação da espécie vegetal bambu, que tem grande capacidade de absorção de dióxido de carbono ${ }^{1}$.

\section{A PROBLEMÁTICA E OS ORGANISMOS LIGADOS À SUSTENTABILIDADE}

As expressões "efeito estufa", "aquecimento global" e "mudanças climáticas" são termos cada vez mais presentes nas discussões referentes ao meio ambiente. $O$ efeito estufa é um fenômeno provocado por três gases que compõem a atmosfera: o dióxido de carbono $\left(\mathrm{CO}_{2}\right)$, gás predominante, o metano $\left(\mathrm{CH}_{4}\right)$ e o óxido nitroso $\left(\mathrm{N}_{2} \mathrm{O}\right)$. Tais gases formam uma película envoltória sobre o planeta, que permite a passagem da luz solar e impede a dissipação de calor, garantindo a temperatura adequada ao planeta. A emissão de uma quantidade excessiva de gases implica no aumento da temperatura natural da atmosfera, contribuindo para as mudanças climáticas.

1 VILLEGAS, Marcelo. New Bamboo Architecure and Design. Bogotá: Villegas editores, 2003. In: Introduction. 
Os impactos decorrentes do aquecimento global propiciaram uma reflexão por parte dos intelectuais, que sensibilizou a Organização das Nações Unidas, instituindo, em 1988, o "Painel Intergovernamental sobre Mudança do Clima". Em 1992, ocorreu a "Conferência das Nações Unidas para o Ambiente e Desenvolvimento", no Rio de Janeiro, a ECO 92. As premissas estabelecidas pela conferência pretendiam estabilizar as emissões dos gases de efeito estufa, segundo os índices alcançados em 1990².

Em seguida, para renovar as premissas pré-estabelecidas, foi criado o protocolo de Kioto, um tratado internacional constituído no Japão, em 1997. Entretanto, a adesão de "55\% dos países emissores" dos gases de efeito estufa foi conseguida somente em 2005. Nesse protocolo, os países assumem como meta cortar 5,2\% de suas respectivas taxas de emissões de gases, até 2012, além de considerar mecanismos para comercializar, em patamares internacionais, os créditos de carbono e aplicar esses investimentos em projetos dos países em desenvolvimento ${ }^{3}$.

Em 1997, o Brasil foi estimado como um dos países em desenvolvimento que mais emitia gases de efeito estufa, em função das queimadas da floresta Amazônica. Nesse sentido, na última década, o Brasil vem reformulando sua política de meio ambiente, visando à maior proteção e flexibilização legal do uso das florestas, por meio do manejo sustentável.

2 VARGAS, Marcelo C. Vargas; RODRIGUES, Diego de Freitas. O Regime Internacional de Mudanças Climáticas e Cooperação Subnacional entre as Grandes Cidades: o caso de São Paulo, Brasil. In: População e Mudança climática: dimensões humanas das mudanças ambientais globais. Campinas: UNICAMP, NEPO; UNFPA, 2009.

3 VARGAS, Marcelo C. Vargas; RODRIGUES, Diego de Freitas. O Regime Internacional de Mudanças Climáticas e Cooperação Subnacional entre as Grandes Cidades: o caso de São Paulo, Brasil. In: População e Mudança climática: dimensões humanas das mudanças ambientais globais. Campinas: UNICAMP, NEPO; UNFPA, 2009. 
A cidade de São Paulo, cria o "Comitê Municipal de Mudanças Climáticas e Ecoeconomia" em $2009^{4}$, com o intuito de buscar ações que visem à mitigação das emissões de gases causadores do efeito estufa. As pesquisas e discussões do Comitê geraram o relatório intitulado "Diretrizes para o plano de Ação da Cidade de São Paulo para Mitigação e Adaptação às mudanças Climáticas"5, em 2011, para implementar a redução de 30\% das emissões desses gases na cidade, até 2012.

Nesse sentido, foram instituídas, na cidade de São Paulo, ações que visam: em primeiro lugar, o "incentivo ao uso de meios de transporte com menor potencial de poluição, fortalecendo o uso de combustíveis renováveis e energia limpa"; em segundo, a "valorização do transporte público e coletivo"; em terceiro, a diminuição "progressiva do uso de combustíveis fósseis"; em quarto o estabelecimento do "programa obrigatório de reciclagem e redução de resíduos sólidos"; em quinto a exigência de obediência a "critérios de eficiência energética e eficiência de materiais em construções" e, ainda, a criação de novos parques lineares e reflorestamento, com plantio de novas árvores, pontos estes que vêm se destacando como melhoria da qualidade de vida. A proposta dos órgãos administrativos da cidade é a criação de 66 novos parques, ampliando a área de 1500 hectares para 5000 hectares.

\section{O ELEMENTO VEGETAL BAMBU E A CAPTAÇÃO DO $\mathrm{CO}_{2}$}

Procurar alternativas que visem promover melhor qualidade de vida no meio urbano, objetivando amenizar o gás carbônico na atmosfera, levou-nos a estudar a gramínea bambu, um recurso natural que cresce e se renova com bastante rapidez, além de ter potencial para absorção de gás carbônico.

4 SÃO PAULO - Município. Decreto no 50.866, de 21 de setembro de 2009. Dispõe sobre as competências, a composição e o funcionamento do comitê municipal de mudança do clima ecoeconomia. Diário Oficial do Município de São Paulo, São Paulo, 22 set. 2009. Disponível em: < www.leismunicipais.com.br> Acesso em: 30 out. 2011.

5 CMMCE - SP - Comitê Municipal de Mudança do Clima e Ecoeconomia do Município de São Paulo. Diretrizes para o plano de Ação da Cidade de São Paulo para Mitigação e Adaptação às Mudanças Climáticas. São Paulo: Prefeitura, 2011. 
Europeus e Americanos começam a enxergar o potencial do bambu, tendo como referência a experiência milenar dos povos orientais. O povo japonês vem utilizando o bambu nos espaços urbanos, especialmente junto ao sistema viário, pois a camada espessa do rizoma, com seu caule subterrâneo, segura as plantas firmemente no lugar, evitando que uma chuva forte espalhe a terra pelas ruas. A poda é realizada todos os anos, promovendo um crescimento curto e denso. Além de conter a erosão, tem considerável importância, devido à alta capacidade de suas folhas de absorver o $\mathrm{CO}_{2}$, convertendo-o em oxigênio, beneficiando o ar do meio urbano.

O bambu é uma planta da família das gramíneas, como a cana de açúcar. Tais plantas são chamadas de " $\mathrm{C}_{4}$ ". Durante o processo de fotossíntese das plantas comuns ${ }^{6}$, ocorre o processo de respiração, absorvendo $\mathrm{O}_{2}$ e liberando uma quantidade de $\mathrm{CO}_{2}$, chamado de "foto respiração". Nas plantas conhecidas como $\mathrm{C}_{4}$, o processo de foto respiração é praticamente ausente, pois estas armazenam em suas fibras o $\mathrm{CO}_{2}$ liberado pela foto respiração de plantas comuns. Segundo Oprins ${ }^{7}$ (2006), pesquisador Belga, durante o crescimento de uma árvore ou bambu, é retirado, da atmosfera, certa quantidade de carbono que fica retido na planta. $\mathrm{O}$ bambu gera mais $\mathrm{O}_{2}$ do que o equivalente a três árvores. Oprins afirma que, na Bélgica, o bambu tem a capacidade de reciclar doze toneladas/hectare de $\mathrm{CO}_{2}$ da atmosfera, produzindo 35\% mais oxigênio do que as árvores na mesma situação, além do fato de ser a planta que apresenta a maior taxa de crescimento da terra. Em média, no primeiro ano, o bambu alcança 70\% de seu tamanho final. Em uma moita brotam, em média, 10 colmos, o que significa um grande potencial de sequestro de carbono. Segundo Maoyi; Yiping ${ }^{8}$ (2002), a "Biomassa da floresta de bambu armazena uma grande quantidade de carbono. Avalia-se que a percentagem de carbono é de $40 \%$ a $45 \%$, quase a metade da biomassa total". Diversos especialistas em função do mercado de crédito de carbono têm pesquisado

6 RAVEN, J. In: Botanical Research. Incorporating Advances in plant pathology. J. A. Calow. School of Biology in Science University of Birghman, Birghman Uk v 27 Academic Press, Boston, 1997.

7 OPRINS, Jan. Trier, Harry van et al. Bamboo: A material for Landscape and Garden Design.

Birkhauser- publishers for Architecture Basel- Berlin-Boston, 2006

8 MAOYI, Fu; YIPING, Lou. 2002. Prospects of research on sustainable management techniques. In: Bamboo for Sustainable Development. In: Proceedings of the $V^{\text {th }}$ International Bamboo Congress and the VIth International Bamboo Workshop, San José, Costa Rica, November 1998. 
a competitividade das espécies de reflorestamento com o bambu. Constatou-se que algumas espécies de bambu, como o Phyllostachys pubescens e a Bambusa, podem ter uma produção de biomassa igual ou superior à de algumas espécies de Eucalyptus. Portanto, o bambu, como elemento vegetal, oferece o que nenhuma outra planta pode propiciar: um grande potencial no sequestro de $\mathrm{CO}_{2}$, em uma área plantada de menor extensão do que outras espécies botânicas.

O bambu é uma planta extraordinária e única. Em função do reconhecimento do potencial do bambu para o meio ambiente, além das inúmeras utilidades para o ser humano, como na produção de papel, de tecido, de móveis, nas construções e nos utilitários do cotidiano, foi criado, no Brasil, no dia 9 de setembro de 2011, uma "lei federal 12.484/2011 que estabelece a Política Nacional de Incentivo ao Manejo Sustentado e ao Cultivo do Bambu".

\section{DISTRIBUIÇÃO E CARACTERÍSTICAS DO ELEMENTO VEGETAL BAMBU}

O bambu é uma planta que se adapta facilmente a diversas condições climáticas e ambientais, como é o caso do clima subtropical ou tropical, ou até mesmo do clima frio, pois já se constatou sua presença na Noruega, sendo nativo das Américas, da Ásia e África. Os únicos continentes que não contam com população nativa de bambu são: a Europa e a Antártica. Na Europa, entretanto, o bambu pode ter existido há milhares de anos atrás, antes de desaparecer na Era Glacial, durante o período Pleistoceno. Os bambus, hoje lá existentes, foram introduzidos na metade do século XVIII. Desde essa introdução, os bambus desenvolveram-se do Mediterrâneo ao Ártico. O único país a não ser tocado, definitivamente, pela gramínea, foi a Antártica.

O Brasil conta com a maior diversidade e o mais alto índice de florestas endêmicas de bambu em toda a América Latina: são mais de 130 espécies, representando 32\% das espécies da América Latina, e 17 gêneros, ou 85\%, sendo que os Estados de São Paulo, Minas Gerais, Santa Catarina, Bahia e Paraná possuem a maior diversidade de espécies de bambu. Entretanto, as grandes áreas de florestas nativas de bambu, estão na Amazônia no Acre e no Pará. A sua presença é mais marcante nas áreas rurais,

9 OSSE, Vera Cristina. Bambu, cultura e paisagem. 2006. Tese Doutorado em Arquitetura e Urbanismo, Universidade de São Paulo, São Paulo, 2006. 
onde são frequentemente utilizados como quebra-ventos, cercas de proteção e cobertura vegetal. As espécies mais comuns no país, hoje, são: Bambusa vulgaris (bambu verde), Bambusa vulgaris var. vitata (bambu imperial), Bambusa tuldoides (bambu comum), Guadua angustifolia, Dendrocalamus giganteus (bambu gigante ou bambu balde) e algumas espécies de Phyllostachys, denominadas bambu chinês. Alguns são nativos, como os pertencentes ao gênero Guadua na região Amazônica, outros foram trazidos para cá pelos portugueses, outros por imigrantes japoneses, e se adaptaram e se expandiram com muita facilidade, principalmente o gênero Phyllostachys ${ }^{10}$.

O bambu revelou-se uma das plantas mais presentes nas culturas tradicionais. Esse fato deve-se ao seu potencial de utilidade, à carga simbólica que carrega e à geração de sentimentos marcantes nos homens, especialmente no Oriente, onde as várias formas de expressão, tanto física, quanto mística e simbólica, perpetuam-se até hoje e são muito valorizadas.

Do ponto de vista taxonômico, o bambu pertence à família das gramíneas, classificado como Bambuseae. Existem mais de mil espécies, agrupadas em 70 gêneros, sem contar aquelas provenientes de regiões inexploradas. Particularmente, no Brasil, estima-se que existam 190 espécies, dado ao clima e ao solo favoráveis ao seu desenvolvimento. Deve-se avaliar a espécie de acordo com a função que irá desempenhar.

O bambu, à semelhança de outras grandes árvores, conserva-se permanentemente verde. A planta não perde as folhas no outono, mas, sim, no início da primavera. Nesse período surgem novas folhas, substituindo gradualmente as velhas. A tenra folhagem decora o jardim, mesmo quando está muito frio, pois o bambu resiste bem à neve.

Após a destruição de Hiroshima, relata-se que foram encontradas hastes verdes de bambu, despontando como anúncio de vida nova. Outras características curiosas da planta é o fato de os novos brotos emergirem do solo com o diâmetro definitivo e o seu crescimento vertiginoso. Apresenta o recorde de velocidade de crescimento, durante o qual é possível, literalmente, ver a planta crescer. O crescimento em altura prolonga-se por três a quatro meses e, depois dessa fase, a planta passa pela maturação, atingindo a maturidade a partir de três a cinco anos. Notadamente, as variedades de

10 OSSE, Vera Cristina. Bambu, cultura e paisagem. 2006. Tese Doutorado em Arquitetura e Urbanismo, Universidade de São Paulo, São Paulo, 2006. 
clima temperado crescem mais rápido do que as de clima tropical. A velocidade de crescimento do bambu revela-se como uma das maravilhas da natureza. Tal crescimento ocorre, geralmente, entre 60 e 90 dias, a partir de sua erupção até o crescimento completo. Por outro lado, a semente de bambu leva de cinco a dez anos para alcançar o completo desenvolvimento e maturidade, e a propagação da espécie se faz mais simples pela divisão de plantas maduras ou pelo plantio de rizomas ${ }^{11}$.

A vantagem do plantio de bambu é que, diferente das demais árvores, este precisa ser plantado uma única vez, reduzindo o custo de produção. A espécie é pouco exigente com o solo, reproduzindo-se melhor quando o ph encontra-se entre 5,5 e 6,5. Apresenta brotações anuais, aumentando a quantidade de colmos a serem colhidos. As colheitas podem ser anuais, porém deve-se fazer uma seleção da idade dos colmos. Os colmos maduros devem ser colhidos a partir de três anos, quando apresentam fibras mais resistentes. Um bambuzal é perene, sendo difícil determinar o seu limite de idade, pois a cada ano surgem novos colmos. Cada colmo individual dura, em média, apenas dez anos, depois disso, seu colmo fica ressecado e morre, caso não tenha sido colhido no devido tempo ${ }^{12}$.

\section{O BAMBU NA COMPOSIÇÃO DO ESPAÇO}

O bambu, por si só, tem um desenho que compõe uma forma arquitetônica significativa no espaço. Dotado de simplicidade, exclusividade e elegância, atua como uma referência, um elemento estruturador no projeto de um jardim.

Na intenção projetual importa considerar o aspecto visual do bambu - forma, tamanho, volume, estrutura, densidade, disposição da folhagem, textura e cor. Pode-se, ainda, considerar inúmeras outras sensações, como, de envoltória, temperatura, odor, escala, enquadramento de visuais, marcos e referências. Segundo o gênero e espécie, o bambu apresenta-se isoladamente ou em grupo, podendo trazer soluções rápidas no

11 OSSE, Vera Cristina. Bambu, cultura e paisagem. 2006. Tese Doutorado em Arquitetura e Urbanismo, Universidade de São Paulo, São Paulo, 2006.

12 FOREST BRAZIL. Plantio florestal do Bambu. In: Viveiro Florestal, Boletim Florestal. Edição 6. Ano 12007. 
processo do projeto, principalmente pela diversidade de porte entre suas espécies: de rasteiro a extra arbóreo, ou em função de seu crescimento rápido.

Dentre as inúmeras possibilidades de utilização do bambu no desenho ambiental pode-se destacar: a recuperação de áreas degradadas, a proteção de nascentes e mananciais de água; a contenção de bordas de áreas de desmatamento; o controle da erosão, pela redução do impacto da chuva no solo; a contenção de encostas íngremes, amenizando a formação de voçorocas; e a criação de volume vegetal com alto potencial de absorção de CO2. Uma das vantagens do seu plantio junto ao meio urbano é o fato de este não requerer espaços amplos e necessitar de pouca profundidade para o seu plantio. Cabe lembrar, todavia, que espécies alastrantes, de rizoma leptomorfo, necessitam de valas protegidas por anteparos nas laterais, para conter a invasão de seus rizomas, restringindo-os ao corredor de plantio.

No Brasil, no estado de Santa Catarina, o bambu está sendo proposto para a recuperação de áreas degradas pela mineração de carvão, principalmente devido à rapidez de seu crescimento, além da elevada taxa de fixação de carbono ${ }^{13}$.

\section{O BAMBU NO ESPAÇO DAS CIDADES}

Os espaços públicos urbanos são espaços de contato com a natureza. Portanto, as praças e os parques são extremamente necessários para a satisfação da vida humana, sendo que a vegetação ameniza a poluição, desempenhando funções ambientais, energéticas e paisagísticas. Um parque tem grande relevância em uma área metropolitana, pois, além de proporcionar o contato com a natureza, também articula as necessidades de lazer e cultura da sociedade urbana contemporânea ${ }^{14}$.

13 ACB-ASSOCIAÇÃO CATARINENSE DO BAMBU. Recuperação de áreas degradadas da mineração de carvão. 2009. Disponível em: <https://docs.google.com/viewer?url=http://www.bambusc. org.br/wp-content/uploads/2009/05/recuperacao-de-areas-degradadas-da-mineracao-de-carvao. ppt\&embedded=true\&chrome=true > acesso em: set. 2010

14 OSSE, Vera Cristina. Bambu, cultura e paisagem. 2006. Tese Doutorado em Arquitetura e Urbanismo, Universidade de São Paulo, São Paulo, 2006. 
Como referência, pode-se destacar o Parque La Villette, em Paris, França, cujo projeto é de grande relevância na escala urbana. O projeto do Parque La Villette foi elaborado por uma equipe coordenada pelo arquiteto Bernard Tschumi, ganhadora de um concurso cuja proposta referenciava-se a novos conceitos para a constituição de um parque urbano do século XXI. O Parque tem um centro cultural a pleno céu aberto, com uma série de programas que articulam a cidade de Paris e sua periferia, abrigando ateliês, ginásios de esportes, quadras esportivas, locais de exposições de arte, áreas de recreação infantil e áreas para concerto, juntas com o Museu de Ciências e da Indústria, além da conhecida Cidade da Música. O Parque La Villette abriga uma série de construções descontínuas, mas perfeitamente articuladas, e está instalado em uma área de 25 hectares, com vários jardins temáticos ${ }^{15}$. Um dos jardins temáticos do Parque La Villette é o Jardim de Bambus, projetado por Alexandre Chemetoff, Madeleine Renan e pelos artistas Bernardo Leitner e Daniel Burer. O jardim é composto por "quarenta espécies diferentes" de bambu, sendo o segundo jardim da França em número de espécies de bambu ${ }^{16}$. A figura 1 a mostra a forma de implantação do jardim de bambu, uma curva sinuosa, e a $1 \mathrm{~b}$ apresenta algumas das espécies plantadas.

Um cuidado especial foi tomado para criar um microclima favorável às diversas espécies de bambu. Para criar um espaço apropriado, a equipe de especialistas recomendou um corte no terreno, implantando o jardim de bambu a seis metros abaixo do nível do parque, protegendo as espécies das intempéries e propiciando menor incidência de ventos (Fig. 2a e 2b). O jardim apresenta um muro de concreto voltado para o sol de meio dia, para produzir uma radiação e gerar calor (Fig. 2a). Como a região apresenta um nível de lençol freático alto, o corte no terreno iria fazer que os brotos ficassem submersos, entretanto, as espécies de bambu gostam de locais com bastante água, mas não crescem em locais submersos, tornando-se necessária uma drenagem especial, que foi realizada para promover as condições ideais ao plantio do bambu ${ }^{17}$.

15 SERPO, ANGELO. Paisagem em MOVIMENTO: o PARQUE ANDRÉ CITROËN em PARIS. Revista Paisagem e Ambiente. Ensaios. São Paulo n. 19 137-162 2003. SAMPART. Parque da Aclimação. <http://www.sampa.art.br/parques/aclimacao/>

16 e 17 ABEN, Rob; WIT, Saskia. The enclosed garden: history and development of the hortus conclusus and its reintroduction into the present-day urban landscape. Rotterdam: @10Publishers, 1999. 

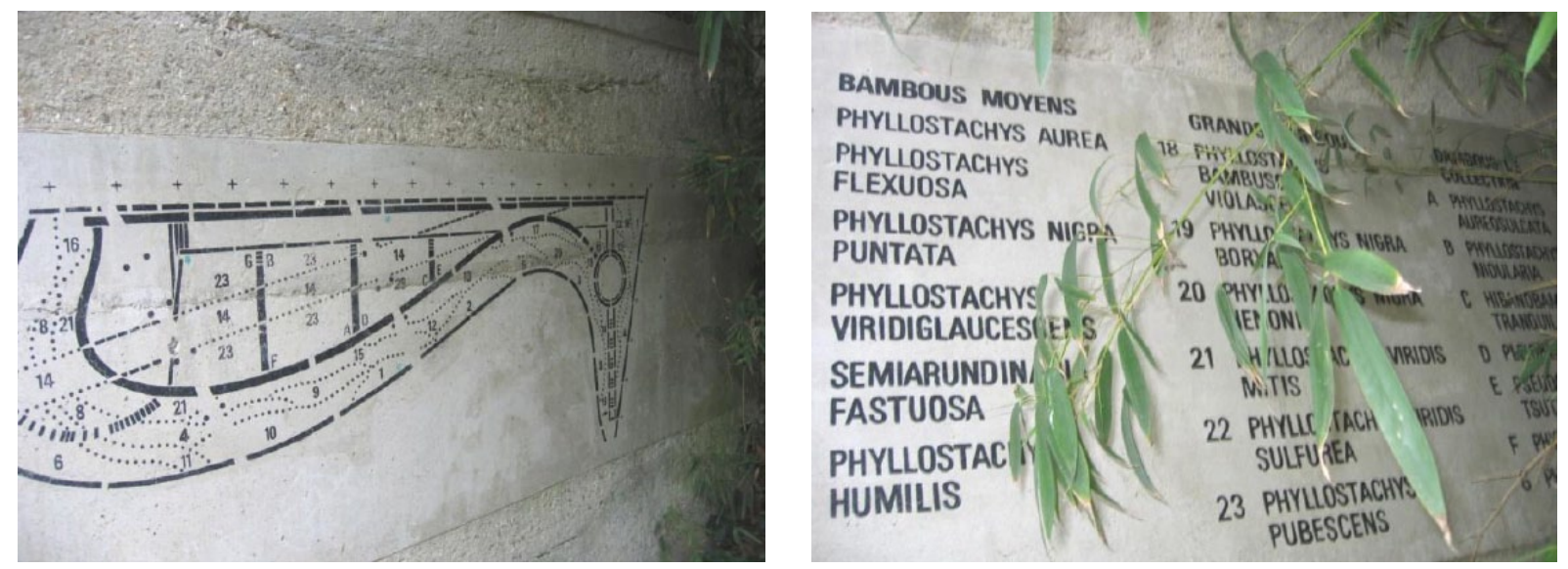

Figura 1: Parque La Villette - Jardim de Bambus. (a) Mapa do jardim enterrado, com caminho sinuoso. (b) Nome de algumas das 40 espécies plantadas. Fonte: acervo da autora Arq. Vera Cristina Osse.
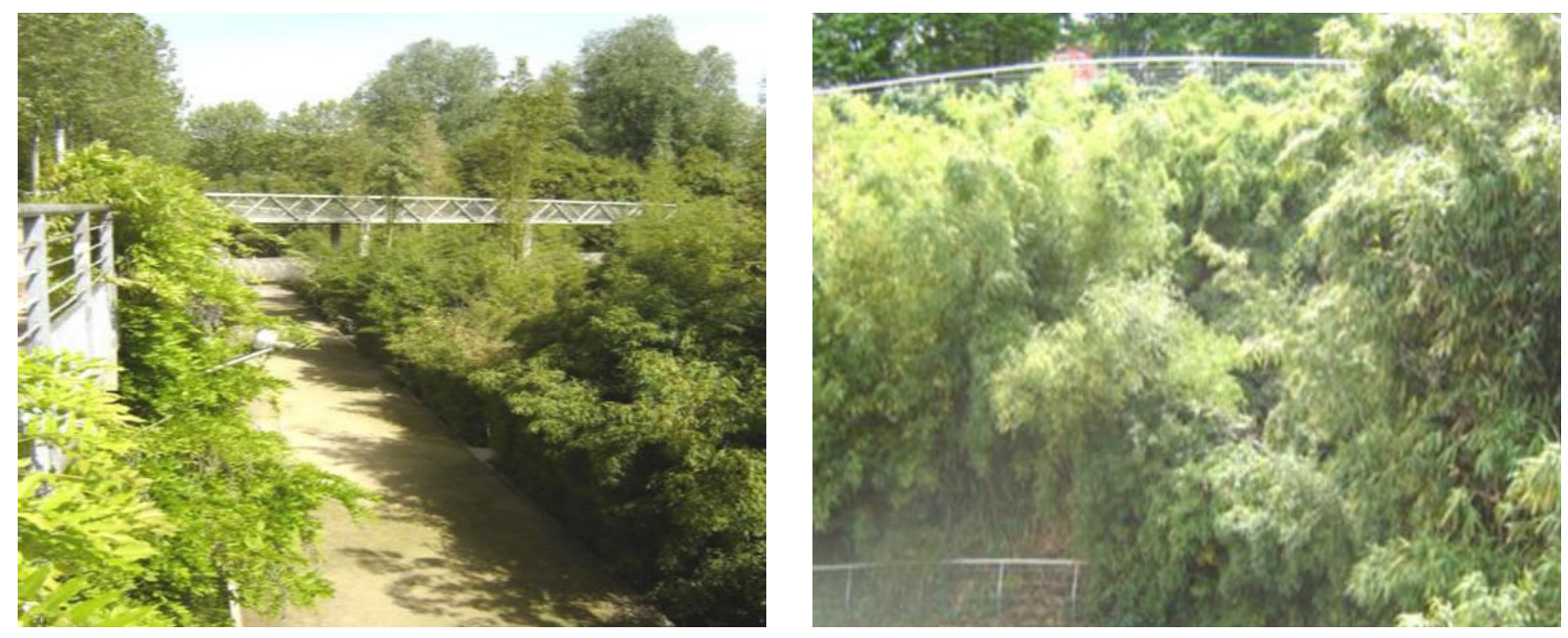

Figura 2: Parque La Villette - Jardim de Bambus. (a) Parede de concreto, passarelas e tubos de drenagem. (b) Espécie de bambu voltada para a luz solar. Fonte: acervo da autora Arq. Vera Cristina Osse.

Esse parque constitui um marco em relação ao cultivo do bambu em espaço público, tratando-se de um plantio estruturado, que vem ao encontro do objetivo desta pesquisa, direcionar e incentivar a presença de bambu no interior das grandes manchas urbanas, principalmente pela captação do $\mathrm{CO}_{2}$, entre outros benefícios.

$\mathrm{Na}$ cidade de São Paulo, existem diversas escalas de parques: instalados em pequenos espaços intersticiais da malha urbana, como o parque Vitor Civita, com 1,3 hectares; focos de recuperação ambiental de áreas degradadas, como o parque do Ibirapuera, um "parque metropolitano" de 158 hectares; e os parques instalados em áreas de preservação ambiental, chamados de APA, como os da Serra da Cantareira 
e da Serra do Mar; além dos parques lineares, que estão sendo implantados principalmente ao longo dos cursos d'água que percorrem a malha urbana da cidade de São Paulo ${ }^{18}$.

Procurando identificar a presença do vegetal bambu, foram realizadas visitas a dois parques da cidade de São Paulo: o Parque Piqueri e o Parque da Aclimação.

O parque do Piqueri, localizado na zona Leste da cidade de São Paulo, junto à marginal do rio Tietê, é uma área que, em "1927, pertencia ao conde Francisco Matarazzo", vindo a se tornar um parque público em 1971. "O parque tem sua história associada à do rio Tietê, .... rio adentrava a chácara antes de seu alinhamento". No local foram encontrados pressupostos de fornos para a produção de tijolos e telhas, pois a várzea do rio foi uma das fontes de materiais como areia e argila, que permitiram a transformação das "construções de taipa na cidade de tijolos"19. Ocupa uma área de 97 hectares, cuja área de vegetação é de 79 hectares. O espaço do parque é voltado ao esporte e ao lazer. Sua vegetação é bastante densa e seu "bosque é heterogêneo". Apresenta uma grande quantidade de eucaliptos, sibipirunas, "araucárias, eritrinas, jerivás, paineiras, alecrins-de-campinas, jatobás, faveiras, paus-ferro, jacarandás-mimosos" e duas espécies de bambus, o Bambusa Vulgaris Vittata e o Bambusa vulgaris ${ }^{20}$. O eixo principal de acesso ao parque é demarcado por uma grande alameda de sibipirunas (Fig. 3a). No final dessa alameda, destaca-se um percurso marcante, delimitado por um túnel de bambus de grande porte, o Bambusa vittata vulgaris (Fig.4a). Outras touceiras de bambu encontram-se junto à divisa do parque com a marginal do Tietê, onde é nítido o seu papel de barreira acústica e visual (Fig. 4b). Estimou-se que a presença do bambu nesse parque equivale a uma média de $3 \%$ do total de sua área verde.

18, 19 e 20 SVMA - SECRETARIA DO VERDE E MEIO AMBIENTE do Município de São Paulo. Guia de parques municipais de São Paulo 2. São Paulo: PMSP, 2010. 

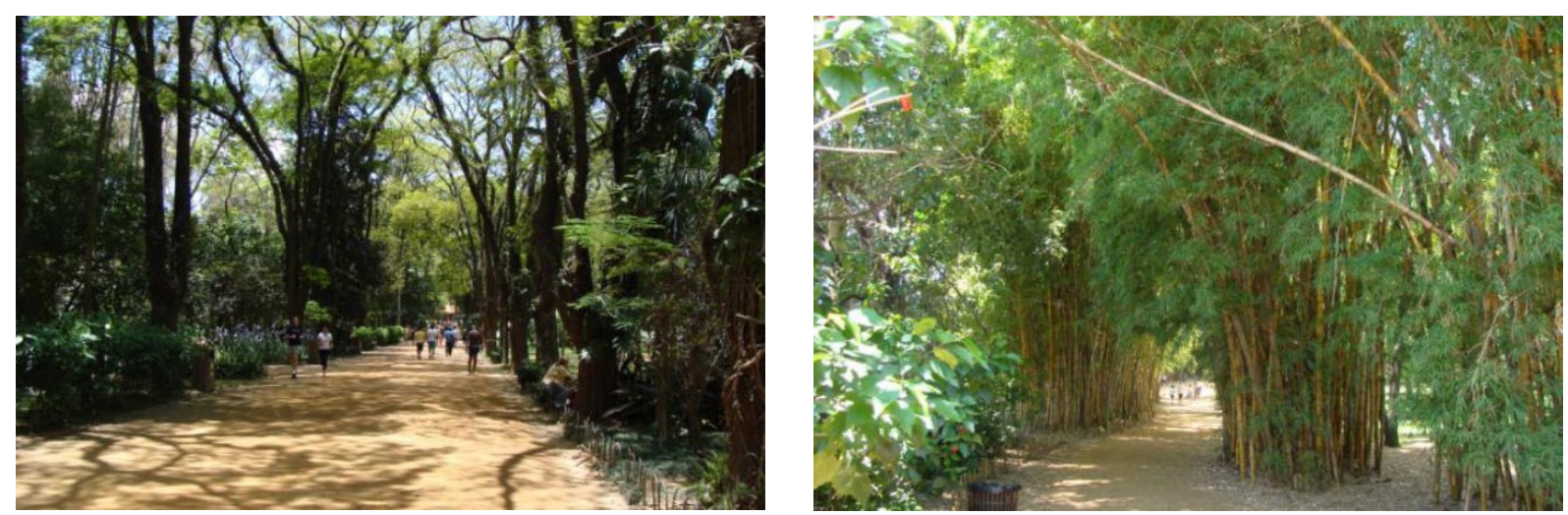

Figura 3: Parque Piqueri. (a) Alameda Sibipiruna. (b) Moita de bambu criando envoltória. Fonte: acervo da autora Célia Meirelles.
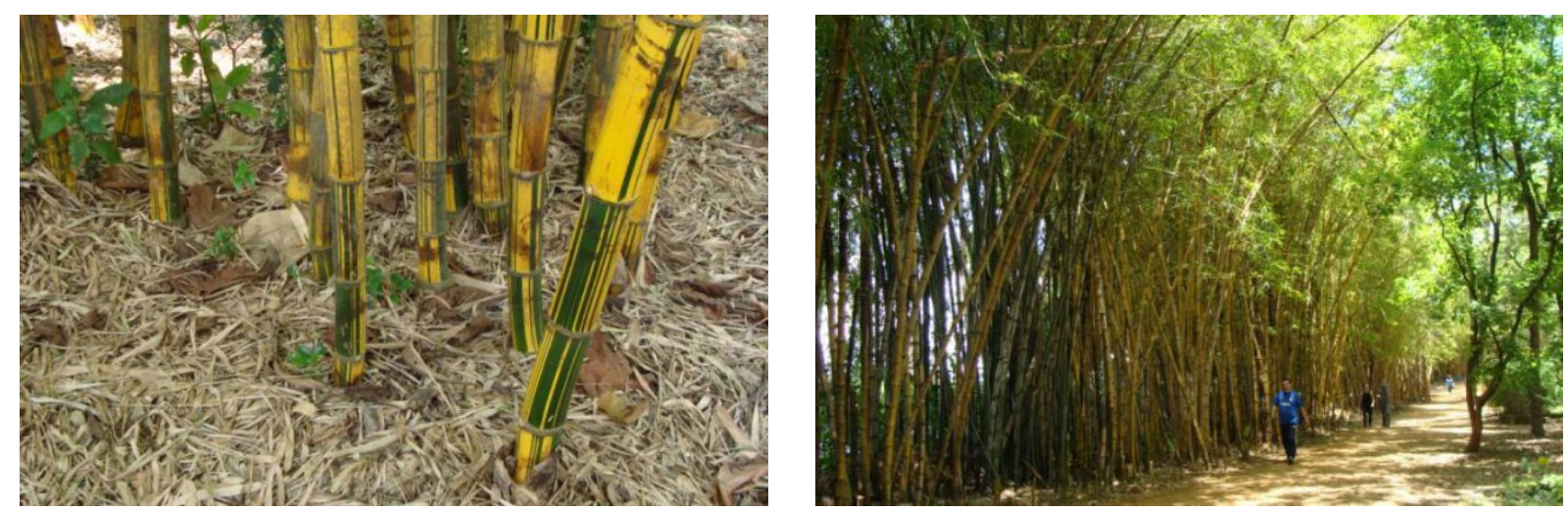

Figura 4: Parque Piqueri. (a) Colmo espécie Bambusa vulgaris vittata. (b) Moita de bambu, divisa do parque com a marginal Tietê, elemento de barreira acústica e visual; elemento de captação de $\mathrm{CO}_{2}$. Fonte: acervo da autora Célia Meirelles.

O Parque da Aclimação é um dos mais antigos da cidade de São Paulo, fundado em 1939, localizado em um fundo de vale, com uma área de aproximadamente 11,8 hectares, cuja área verde equivale a 6,5 hectares, onde se destaca o grande lago, que propicia um microclima agradável para os dias quentes de verão ${ }^{21}$. O espaço do parque é voltado para o lazer e o esporte, além do foco cultural inserido com a presença de uma "biblioteca de meio ambiente"22. Estão presentes diversas espécies de árvores nativas e exóticas, como eucaliptos, "pinheiro-do-paraná, amoreiras, jacarandás-mimosos, sibipirunas" e outras, além de sete grandes touceiras de bambu.

21 SAMPART. Parque da Aclimação. <http://www.sampa.art.br/parques/aclimacao/>

22 SVMA - SECRETARIA DO VERDE E MEIO AMBIENTE do Município de São Paulo. Guia de parques municipais de São Paulo 2. São Paulo: PMSP, 2010. 
Esses bambus, segundo um dos conselheiros do parque, foram plantados há aproximadamente cinco anos, com a intenção de conter os deslizamentos de terra das partes mais elevadas do parque. Uma das touceiras está junto ao portão de entrada, na Rua Muniz de Souza (Fig. 5a), e as outras nas proximidades do portão 4 e 5, junto à Rua Ametista e Rua Pedra Azul (Fig. 6a e 6b). Estimamos que a área de bambu no Parque da Aclimação é pequena, o equivalente a 0,1\% da área verde total, permitindo ampliações de uso deste elemento vegetal.
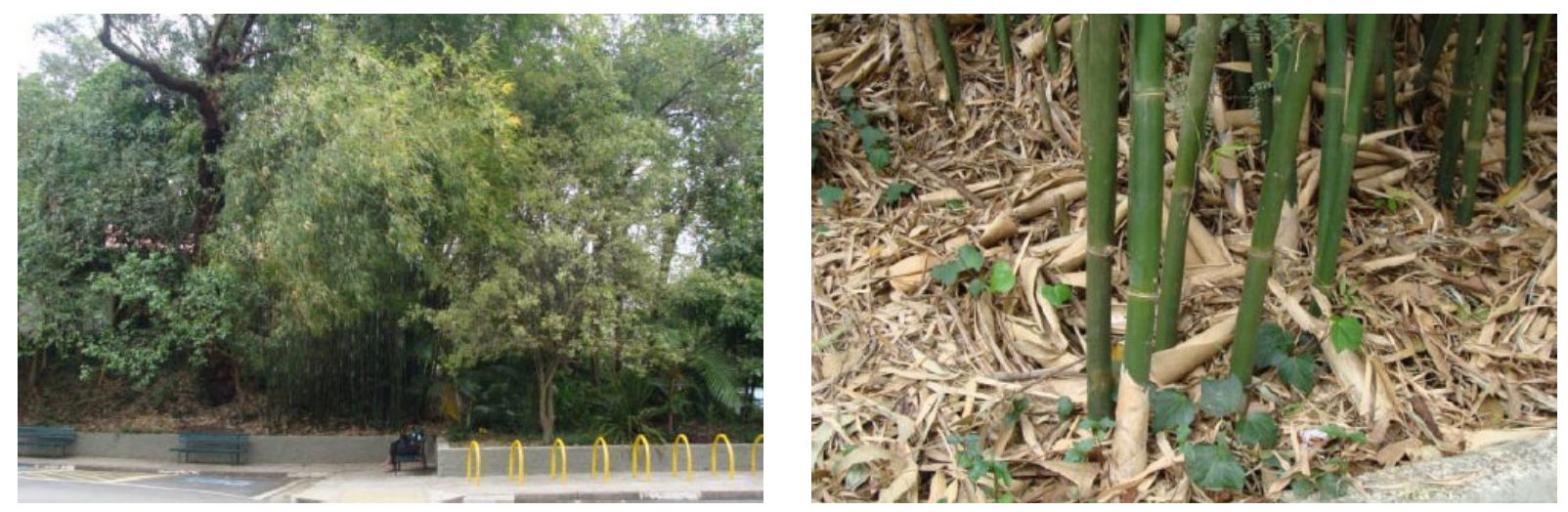

Figura 5: Parque da Aclimação. (a) Bambu torna local aconchegante em dia de calor. Fonte: acervo da autora Célia Meirelles.
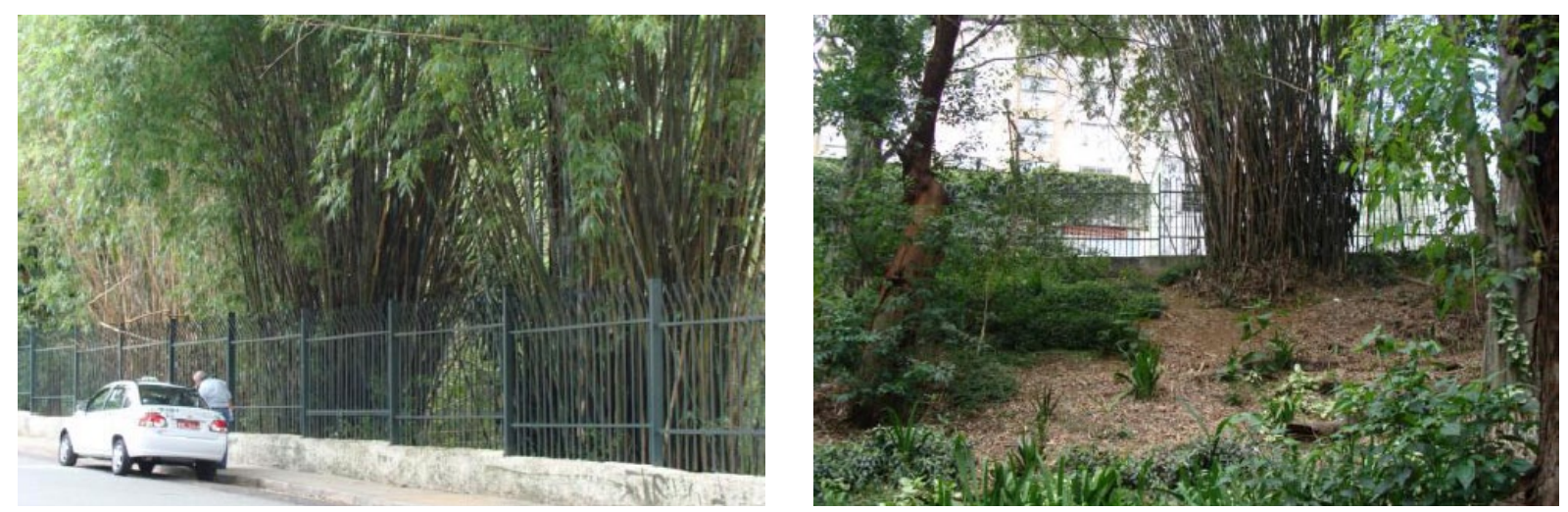

Figura 6: Parque da Aclimação. R. Pedra Azul. (a) Vista externa: touceira de Bambu. (b) Vista interna: bambu contenedor do solo. Fonte: acervo da autora Célia Meirelles.

Ao se planejar uma ampliação do plantio de espécies nesses parques, será importante destacar um plano de manejo voltado ao plantio de Bambus. Pode-se afirmar que uma área plantada com bambu apresenta uma capacidade de captar $\mathrm{CO}_{2}$ superior à de florestas plantadas em eucalipto, de quase duas vezes ou mais. O plantio de bambu em jardins, parques lineares e parques não somente irá proporcionar à cidade um espaço de saúde, mas também a recuperação de áreas degradadas. Outro ponto de relevância é a criação de centro de pesquisa, voltado ao plantio dessa espécie, que 
poderá gerar e viabilizar, para a cidade, créditos de carbono que proporcionarão novos investimentos em construções e na formação de técnicos e pesquisadores.

\section{CONCLUSÃO}

A pesquisa destaca a importância do bambu como elemento vegetal de grande potencial na minimização dos problemas climáticos, especialmente nos grandes centros urbanos, devido à sua capacidade de capturar o $\mathrm{CO}_{2}$ e à contenção de erosões de forma natural. Constatou-se uma referência relevante no Parque La Villette, em Paris, onde o jardim se torna uma experimentação viva, abrigando quarenta diferentes espécies que, apesar de não serem nativas da França, fazem parte integrante de pesquisas voltadas ao meio ambiente.

Na grande maioria dos parques da cidade de São Paulo, a presença do bambu é pontual. O parque do Piqueri abriga uma quantidade um pouco mais significativa, que pode atuar na minimização do $\mathrm{CO}_{2}$ e também como barreira visual e acústica, junto ao sistema viário da marginal do rio Tietê.

O plantio do bambu, na cidade, pode vir a potencializar os benefícios, de forma direta e indireta, relativos à amenização das mudanças climáticas, atuando na redução de temperatura, na purificação do ar, na contenção dos problemas de erosão e deslizamentos de encostas, na redução das enchentes, e também na implementação de uma composição estética no desenho da paisagem, propiciando locais de bem-estar para a população.

No escopo dessa perspectiva, a criação de um centro de pesquisa voltado para o cultivo do bambu, junto à administração de Áreas verdes da Cidade de São Paulo, é de grande relevância para o domínio tecnológico das espécies e para a melhoria da qualidade de vida na região metropolitana.

\section{REFERÊNCIAS BIBLIOGRÁFICAS}

ABEN, Rob; WIT, Saskia. The enclosed garden: history and development of the hortus conclusus and its reintroduction into the present-day urban landscape. Rotterdam: @10Publishers, 1999. 
ACB-ASSOCIAÇÃO CATARINENSE DO BAMBU. Recuperação de áreas degradadas da mineração de carvão. 2009. Disponível em: <https://docs.google.com/ viewer?url=http://www.bambusc.org.br/wp-content/uploads/2009/05/recuperacaode-areas-degradadas-da-mineracao-de-carvao.ppt\&embedded=true\&chrome=true> acesso em: set. 2010.

BRASIL. Lei no 12.484/2011 - 9 de setembro de 2011. Institui a Política Nacional de Incentivo ao Manejo Sustentado e ao Cultivo do Bambu. Diário Oficial da União, Brasília, DF, 9 set. 2011. Disponível em: <http://www.observatorioeco.com.br/lei-criapolitica-de-incentivo-ao-cultivo-do-bambu/> acesso em: 30/set/2011.

CMMCE- SP - Comitê Municipal de Mudança do Clima e Ecoeconomia do Município de São Paulo. Diretrizes para o plano de Ação da Cidade de São Paulo para Mitigação e Adaptação às Mudanças Climáticas. São Paulo: Prefeitura, 2011.

FOREST BRAZIL. Plantio florestal do Bambu. In: Viveiro Florestal, Boletim Florestal. Edição 6. Ano 1, 2007.

MAOYI, Fu; YIPING, Lou. 2002. Prospects of research on sustainable management techniques. In: Bamboo for Sustainable Development. In: Proceedings of the Vth International Bamboo Congress and the VIth International Bamboo Workshop, San José, Costa Rica, November 1998.

OPRINS, Jan. Trier, Harry van et al. Bamboo: A material for Landscape and Garden Design. Birkhauser- publishers for Architecture Basel- Berlin-Boston, 2006.

OSSE, Vera Cristina. Bambu, cultura e paisagem. Tese Doutorado em Arquitetura e Urbanismo, Universidade de São Paulo, São Paulo, 2006.

RAVEN, J. In: Botanical Research. Incorporating Advances in plant pathology. J. A. Calow. School of Biology in Science University of Birghman, Birghman Uk v 27 Academic Press, Boston,1997.

SAMPART. Parque da Aclimação. <http://www.sampa.art.br/parques/aclimacao/>

SERPO, ANGELO. Paisagem em MOVIMENTO: o PARQUE ANDRÉ CITROËN em 
PARIS. Revista Paisagem e Ambiente. Ensaios. São Paulo n. 19 137-162 2003

SÃO PAULO - Município. Decreto n 50.866, de 21 de setembro de 2009. Dispõe sobre as competências, a composição e o funcionamento do comitê municipal de mudança do clima e ecoeconomia. Diário Oficial do Município de São Paulo, São Paulo, 22 set. 2009. Disponível em: < www.leismunicipais.com.br> Acesso em: 30 out. 2011.

SVMA - SECRETARIA DO VERDE E MEIO AMBIENTE do Município de São Paulo. Guia de parques municipais de São Paulo 2. São Paulo: PMSP, 2010.

SVMA - SECRETARIA DO VERDE E MEIO AMBIENTE do Município de São Paulo. Síntese do Inventário de Emissões de Gases de Efeito Estufa do Município de São Paulo. Centro Clima/COPPE/UFRJ. Secretaria do Verde e do Meio Ambiente, SãoPaulo, 2005. Disponivel em: http://www.prefeitura.sp.gov.br/arquivos/secretarias/meio_ambiente/Sintesedoinventario.pdf. acesso em: jun. de 2011

VARGAS, Marcelo C. Vargas; RODRIGUES, Diego de Freitas. O Regime Internacional de Mudanças Climáticas e Cooperação Subnacional entre as Grandes Cidades: o caso de São Paulo, Brasil. In: População e Mudança climática: dimensões humanas das mudanças ambientais globais. Campinas: UNICAMP, NEPO; UNFPA, 2009.

VILLEGAS, Marcelo. New Bamboo Architecure and Design. Bogotá: Villegas editores, 2003. 